\title{
RFT5-dgA Immunotoxin IMTOX25
}

National Cancer Institute

\section{Source}

National Cancer Institute. RFT 5-dgA Immunotoxin IMTOX25. NCI Thesaurus. Code C61498.

A recombinant immunotoxin consisting of the anti-CD25 monoclonal antibody RFT 5 fused to the deglycosylated ricin A-chain (dgA) with potential antitumor activity. The monoclonal antibody moiety of RFT 5-dgA immunotoxin attaches to CD25 (the alpha chain of the IL-2 receptor complex) on the cell membrane; after internalization, the $d g A$ moiety cleaves the $\mathrm{N}$-glycosidic bond between the ribose and adenine base at position 4324 in 285 ribosomal RNA, resulting in ribosome inactivation, inhibition of protein synthesis, and cell death. CD25 is expressed on activated normal T and B cells and macrophages and is frequently upregulated in many hematologic malignancies. 